\title{
Influenza vaccine coverage, awareness, and beliefs regarding seasonal influenza vaccination among people aged 65 years and older in Central Saudi Arabia
}

Fawzan Y. Alotaibi, Medical Students, Abdulkarim F. Alhetheel, Msc, PhD, Yousef M. Alluhaymid, Medical Students,

Mohammed G. Alshibani, Medical Students, Abdulkarim O. Almuhaydili, Medical Students, Talal A. Alhuqayl, Medical Students,

Fahad M. Alfayez, Medical Students, Ahmed A. Almasabi, Medical Students.

$$
\begin{aligned}
& \text { ABSTRACT } \\
& \text { الأهداف : دراسة مستوى الوعي ومصدر المعلومة والمعتقدات عن }
\end{aligned}
$$

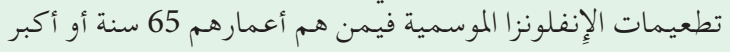

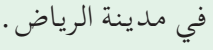

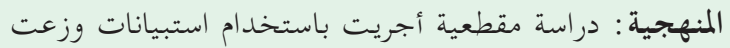

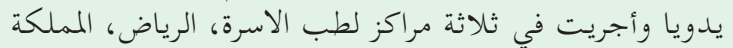

$$
\begin{aligned}
& \text { العربية السعودية. }
\end{aligned}
$$

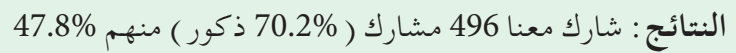

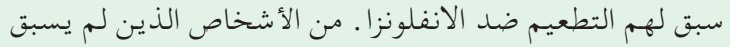

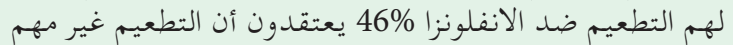

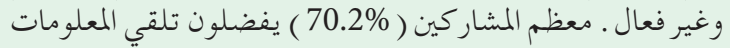

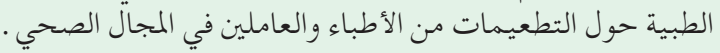

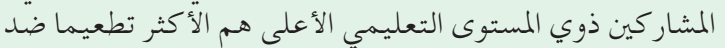

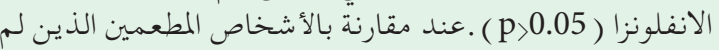

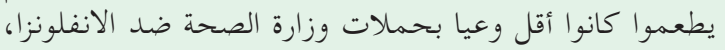

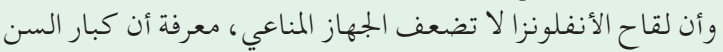

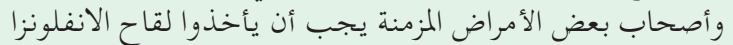

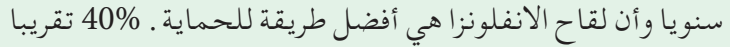

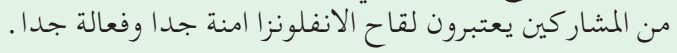

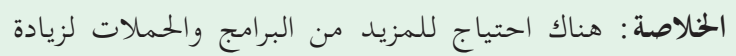

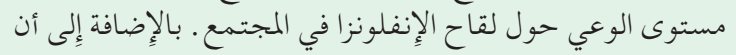

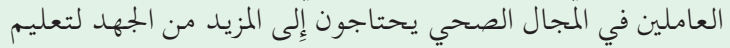

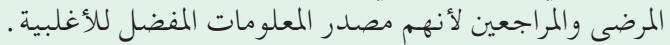

Objectives: To investigate the level of awareness, sources of knowledge, and beliefs about the influenza vaccine in people $\geq 65$ years in central Saudi Arabia.

Methods: A cross-sectional study that used self-administered questionnaires conducted in 3 primary healthcare centers in Riyadh, Saudi Arabia between May 2018 and August 2018.
Results: There were 496 Saudis participants $(70.2 \%$ male) were included, of whom, $47.8 \%$ had been vaccinated against influenza at least once. Of unvaccinated individuals, $46 \%$ believed that the vaccine was unnecessary. The majority of participants (70.2\%) preferred to receive medical information on vaccination from doctors and health workers. Participants with higher levels of education were significantly more likely to have been vaccinated $(p<0.05)$. Compared to the vaccinated participants, unvaccinated individuals were significantly less likely to be aware of the Ministry of Health campaign against influenza, believe that influenza vaccine does not weaken the immune system, know that elderly people and people with long-standing health problems should be regularly vaccinated against influenza, and believe that the influenza vaccine was the best way of prevention. Approximately $40 \%$ of the participants considered the influenza vaccine to be very effective and safe.

Conclusions: There is a need for further programs in order to increase the awareness level of influenza vaccination. Also, health workers need to make more effort to educate patients because they are the preferred source of information.

Saudi Med J 2019; Vol. 40 (10): 1013-1018 doi: 10.15537/smj.2019.11.24587

From the College of Medicine (Alotaibi, Alluhaymid, Alshibani, Almuhaydili, Alhuqay, Alfayez, Almasasbi), King Saud University, and from the Department of Microbiology \& Pathology (Alhetheel), King Khalid University Hospital, Riyadh, Kingdom of Saudi Arabia.

Received 13th June 2019. Accepted 17th September 2019.

Address correspondence and reprint request to: Dr. Fawzan Y. Alotaibi, College of Medicine, King Saud University, Riyadh, Kingdom of Saudi Arabia.E-mail: fawzanyousef01@gmail.com

ORCID: https://orcid.org/0000-0002-3757-3262 
I nfluenza is a highly infectious, epidemic viral illness. The disease has social and economic repercussions, making it a major health concern. There are 3 basic types of influenza viruses, they are $\mathrm{A}, \mathrm{B}$, and $\mathrm{C}$. The type A influenza virus affects people of different ages, causing moderate to severe illness and infects other animals. The type B influenza virus usually causes illness milder than the type A Influenza virus and affecting children. The type $\mathrm{C}$ virus rarely reported in humans because the majority of cases are subclinical and it is not an epidemic disease. ${ }^{1}$ Influenza infection occurs worldwide and usually peaks during the winter, with an estimation of up to $5,000,000$ cases and up to 500,000 deaths annually. ${ }^{2,3}$ In the majority of the population, influenza is a self-limiting disease. ${ }^{4}$ However, in elderly people, those who are immunocompromised, pregnant women, infants, and individuals with chronic diseases, it may present as a severe illness requiring hospitalization. ${ }^{1,2}$ The complications of influenza include acute myocardial infarction and cardiovascular deaths, neurological complications, renal failure, and superimposed infections. Influenza vaccines have been available 70 years ago and have modified over time. ${ }^{1,5-8}$ The recommendation is that everyone over the age of 6 months must receive the influenza vaccination annually, unless contraindicated. The annual influenza vaccine is especially important for people who are susceptible to developing a severe illness as it is the most efficient way for the primary prevention of the illness and its consequences. ${ }^{9}$ Annual vaccination is cost-effective, especially among those such as elderly peoples, who are susceptible to developing severe disease. ${ }^{10}$ The World Health Organization (WHO) Global Vaccine Action Plan (GVAP) goal is to increase the prevention of all preventable infections. The main goal is to ensure national vaccine coverage rates of at least $90 \% .{ }^{11}$ For influenza, the GVAP goal to elevate the uptake and coverage of annual flu vaccination. ${ }^{12}$ Even though influenza vaccination is considered important, previous studies in the Gulf region and Jordan have shown low rates of vaccination. In the Gulf region, the coverage of the influenza vaccine was $17 \%$ and the main cited reason for not being vaccinated is not being aware of the vaccine. In regard to the Jordan rate of seasonal influenza

Disclosure. Authors have no conflict of interests, and the work was not supported or funded by any drug company. vaccine coverage ranged from $9.9 \%$ to $27.5 \%$ and the most common misbelief was fear of side effects. ${ }^{13,14}$ Overall, influenza vaccine uptake in countries in the Gulf region is suboptimal compared to other regions, although it varies widely between countries, and further research on vaccine coverage is needed. ${ }^{13,15,-19}$ Every year, a considerable number of Muslims from all over the world go on pilgrimages to the holy cities of Mecca and Medina. These massive gatherings of human beings can potentially import many influenza strains to Saudi Arabia. Furthermore, the worldwide transmission of influenza is probable once the pilgrims return to their home countries. Fortunately, the influenza transmission is reduced by weather nature in these 2 holy cities, as well as by optimal hygiene systems supervised and sponsored by the Saudi government. However, the influenza transmission cannot completely be controlled. ${ }^{20}$ Health Ministry in Saudi Arabia provides flu vaccines every year, free for anyone older than 6 months. ${ }^{21}$ The importance of regular seasonal flu vaccination is clarified in diverse social media and health care providers, also on Saudi Health Ministry website, especially before the pilgrimage time. Although, some studies in Saudi Arabia have shown that pregnant ladies and healthcare workers are refusing to take a seasonal flu vaccine. Although these studies had some limitations, such as inability to generalize the findings due to the fact that they were conducted at a single hospital and during only one influenza season. ${ }^{15,22}$ In Saudi Arabia, there is a progressive increment in vaccination coverage and rate from $17.8 \%$ in 2009 to $44.5 \%$ in 2018 and the most common misbeliefs about influenza vaccination was fear of side effects. However, these studies had not concentrated on a specific age group while a study carried out in Colombia focused on 65 years old and older individuals in 2018, the vaccination rate was $79 \%$ and the most common misbelief was fear of side effects. ${ }^{16-19}$

This study aimed to measure the level of awareness, coverage and beliefs regarding seasonal influenza vaccination among people aged 65 years and older, since the risk is increasing in this age group and other comorbidities may make them at higher risk of influenza complications.

Methods. We conducted a quantitative, observational cross-sectional study among people aged 65 years and older who visited primary healthcare centers at 3 hospitals in Riyadh City, Saudi Arabia between May 2018 and August 2018. Participants were asked to 
complete a self-administered questionnaire, which had been used in a previous study. ${ }^{17}$ The questionnaire was modified and the pilot study was carried out on 20 participants. Participants' selection was convenience. Inclusion criteria were Saudis and aged 65 years and older. The questionnaire was distributed at different sites on different dates. To ensure that there is no duplication of the data collected, each participant was given one questionnaire and asked to complete it and hand it back when it is carried out. Also, the participants were asked to fill up the questionnaire onetime to ensure there is no duplication in the data.

Study approval was obtained from College of Medicine Research Center, King Saud University, Riyadh, Saudi Arabia. The sentence "completion of the following questionnaire will be taken as an indication of your consent to participate" was added at the top of the questionnaire form as a method of obtaining informed consent.

Sample size calculations estimated that the minimum sample size required was 348. This was estimated by using the sample size calculation for a single proportion: $\mathrm{N}=(\mathrm{z})^{*} 2 \mathrm{p}^{*}(1-\mathrm{p}) / \mathrm{d} 2$, where $\mathrm{p}$ is the proportion, and $\mathrm{d}$ is the margin of error, with a 0.5 proportion regarding pilot study, 95\% confidence level and 5\% margin of error. We added $10 \%$ to the target sample size in order to make allowance for incomplete questionnaires, bringing the target sample size to 383 .

Data analyzed by using Statistical Package for Social Studies (SPSS 22; IBM Corp., New York, NY, USA). Categorical variables were expressed as percentages. The Chi-square test and Fisher's Exact test were used to assess statistical significance in comparisons of categorical variables. A $p$-value $<0.05$ was considered to be statistically significant.

Results. Of the 608 completed surveys, 496 were eligible for analysis of whom 348 (70.2\%) were male. Overall, 237 (47.8\%) of the participants had received a seasonal influenza vaccine at least once in their lives, and $259(52.2 \%)$ had never been vaccinated. Of the participants, 199 (40.1\%) believed that the influenza vaccine was very effective, $217(43.8 \%)$ believed that it was very safe, and $348(70.2 \%)$ stated that doctors and health workers were their preferred source of medical information about vaccination.

There is no significant association between population characteristics and influenza vaccine status except that those with a higher level of education were significantly more likely to be vaccinated $(p<0.05)$. (Table 1).
Of the 259 participants who had not been vaccinated, $119(46 \%)$ believed that the vaccine was unnecessary, $70(27 \%)$ were unaware that there was a vaccine for influenza, 63 (24.3\%) were worried about the safety of the vaccine in regard to complications and side effects, and 7 (2.7\%) had not been vaccinated due to other reasons.

Of the participants, 237 (47.8\%) had been evervaccinated against influenza at least once, and 259 (52.2\%) had never been vaccinated. Of those who had been vaccinated against influenza at least once, $88(37.1 \%)$ had been vaccinated regularly in every influenza season, and 120 (50.6\%) had been vaccinated in the previous influenza season.

Regarding the efficacy and safety of the influenza vaccine, there were 4 answers for each category, these answers are very effective or safe, somewhat effective or safe, somewhat ineffective or unsafe, very ineffective or unsafe. For efficacy, 199 (40.1\%) believed that the vaccine was very effective, $133(67 \%)$ of them were vaccinated. For safety, $217(43.8 \%)$ believed that the vaccine was very safe, $144(66.4 \%)$ of them were vaccinated.

Compared to the participants who had not been vaccinated, those who had been vaccinated were

Table 1 - Association between population characteristics and influenza vaccine status) $(\mathrm{N}=237)$.

\begin{tabular}{|c|c|c|c|c|}
\hline \multirow{3}{*}{$\begin{array}{l}\text { Characteristic } \\
\text { Gender }\end{array}$} & \multirow[t]{2}{*}{$\mathrm{N}$} & \multicolumn{2}{|c|}{ Ever-vaccinated } & \multirow[t]{2}{*}{$P$-value } \\
\hline & & $\mathrm{n}$ & (\%) & \\
\hline & & & & 0.261 \\
\hline Male & 348 & 172 & $(49.4)$ & \\
\hline Female & 148 & 65 & (43.9) & \\
\hline Educational level & & & & 0.029 \\
\hline High school or less & 305 & 139 & $(45.6)$ & \\
\hline University & 153 & 72 & $(47.1)$ & \\
\hline Postgraduate studies & 38 & 26 & $(68.4)$ & \\
\hline Practicing in medical field & & & & 0.629 \\
\hline Yes & 51 & 26 & $(51.0)$ & \\
\hline No & 445 & 211 & $(47.4)$ & \\
\hline Frequency of use of search engines & & & & 0.280 \\
\hline Daily & 212 & 112 & $(52.8)$ & \\
\hline Weekly & 73 & 36 & $(49.3)$ & \\
\hline Monthly & 24 & 11 & $(45.8)$ & \\
\hline Rarely & 37 & 16 & $(43.2)$ & \\
\hline Never & 150 & 62 & $(41.3)$ & \\
\hline Frequency of use of social media & & & & 0.167 \\
\hline Daily & 278 & 145 & $(52.2)$ & \\
\hline Weekly & 53 & 24 & $(45.3)$ & \\
\hline Monthly & 9 & 5 & $(55.6)$ & \\
\hline Rarely & 24 & 8 & (33.3) & \\
\hline Never & 132 & 55 & (41.7) & \\
\hline
\end{tabular}


Table 2 - Participants' level of awareness regarding influenza vaccination.

\begin{tabular}{|c|c|c|c|c|c|c|}
\hline \multirow{3}{*}{$\begin{array}{l}\text { Statement } \\
\text { Aware that the Ministry of Health has } \\
\text { campaigns against seasonal influenza }\end{array}$} & \multirow{2}{*}{$\begin{array}{c}\begin{array}{c}\text { Awareness } \\
\text { status }\end{array} \\
\text { Yes }\end{array}$} & \multicolumn{2}{|c|}{$\begin{array}{l}\text { Ever-vaccinated } \\
\quad(\mathbf{n}=237)\end{array}$} & \multicolumn{2}{|c|}{$\begin{array}{l}\text { Non vaccinated } \\
\quad(\mathrm{n}=259)\end{array}$} & \multirow{3}{*}{$\begin{array}{l}P \text {-value } \\
<0.001\end{array}$} \\
\hline & & 154 & $(65.0)$ & 92 & $(35.5)$ & \\
\hline & No & 83 & $(35.0)$ & 167 & $(64.5)$ & \\
\hline \multirow{2}{*}{$\begin{array}{l}\text { Aware that the influenza vaccine does not } \\
\text { weakens the immune system }\end{array}$} & Yes & 128 & $(54.0)$ & 75 & $(29.0)$ & \multirow[t]{2}{*}{$<0.001$} \\
\hline & No & 109 & $(46.0)$ & 184 & $(71.0)$ & \\
\hline \multirow{2}{*}{$\begin{array}{l}\text { Aware that the elderly and people with } \\
\text { chronic health problems they better get a } \\
\text { vaccine for seasonal influenza }\end{array}$} & Yes & 105 & (44.3) & 61 & $(23.6)$ & \multirow[t]{2}{*}{$<0.001$} \\
\hline & No & 132 & $(55.7)$ & 198 & $(76.4)$ & \\
\hline \multirow{2}{*}{$\begin{array}{l}\text { Aware that the best way of protection } \\
\text { from influenza is the influenza vaccine }\end{array}$} & Yes & 156 & $(65.8)$ & 61 & (23.6) & \multirow[t]{2}{*}{$<0.001$} \\
\hline & No & 81 & (34.2) & 198 & (76.4) & \\
\hline
\end{tabular}

significantly aware of the seasonal influenza vaccine in regard to the Ministry of Health campaigns against seasonal influenza, the seasonal influenza vaccine does not weakens the immune system, the elderly and people with chronic health problems they better get the seasonal influenza vaccine, and the best way of protection of seasonal influenza is the vaccine $(p<0.001$ for each statement) (Table 2).

Discussion. The goal of the study was to investigate the current level of awareness, sources of knowledge, and beliefs about the influenza vaccine in people aged 65 years and older in Riyadh in Saudi Arabia. The number of people living in Saudi Arabia aged 65 years and older is estimated to be 854,281 , which considerable number. ${ }^{23}$ More than half of the participants are not vaccinated against influenza, and the majority of those who had not been vaccinated believed that influenza vaccination was unnecessary. These findings are a cause for concern as it places a burden on healthcare providers to change these beliefs among this age group members of the public. The majority of participants stated that doctors and health workers were their preferred source of medical information about vaccination. Education plays a role in the level of awareness regarding influenza vaccination. In this study, the more educated had a higher level of awareness regarding influenza vaccination than those who had less education. Approximately $40 \%$ of the participants thought that the influenza vaccine was very effective and very safe.

In this study, we found that $47.8 \%$ of the participants had been vaccinated against influenza. A study of influenza vaccination among military staff in Saudi Arabia, conducted in 2009, found that $17 \%$ of the participants overall had been vaccinated against influenza, but recently the level of vaccine coverage was considerably higher (36.7\%) in Riyadh City than elsewhere in the region. ${ }^{16,18}$ Another survey of influenza vaccine coverage in Saudi Arabia conducted in 2017 found that $44.5 \%$ of the participants had been vaccinated. ${ }^{17}$ Other reports of influenza vaccine coverage in countries such as Middle East $(27.5 \%)^{13}$ and Arabian Gulf countries (17\%) had been vaccinated. ${ }^{14}$ Despite reported variations according to age this study focused on 65 years and older individuals while the other studies were for 18 years and older, the level of influenza vaccine coverage has increased in Saudi Arabia. This remarkable progress may be due to the significant efforts and campaigns by the Saudi Ministry of Health. A recent study conducted on 65 and older individuals living in Colombia found that $79 \%$ of the participants were vaccinated. ${ }^{19}$ These contrasting results may reflect large differences between 2 societies in terms of culture, educational health programs, and health insurance.

In this study, we found that the most common reason given for not being vaccinated was that the vaccine was unnecessary. In contrast to this finding, other studies found that the most common reason given for not being vaccinated was a fear of side effects. ${ }^{14,18,-19}$ These contrasting findings may be attributable to the varying importance given to risks versus benefits. The variation between studies in the age of participants since these studies were for 18 years and older except Rikin et $\mathrm{al}^{19}$ study was addressing the same age group. In regard to Rikin et $\mathrm{al}^{19}$ study as mentioned before, large differences between 2 societies may have played a role, also, when we look to Table 2, the majority of non-vaccinated people they had no awareness and knowledge regarding the influenza vaccination. So, this lack of knowledge likely contributes to the fact that the majority of people do not consider the influenza vaccination necessary.

Forty percent of participants in this study considered the influenza vaccine to be very effective and very safe. This is almost same as the finding in a previous study 
that carried out in the same age group by Rikin et al. ${ }^{19}$ Our study findings are in line with our hypothesis because all previous studies in risky populations have had similar findings that negative beliefs regarding the influenza vaccination were associated with lower rates of vaccine uptake, and that a higher level of vaccine uptake was associated with a higher level of education, although there is variation between this study and other studies except for Rikin et al study regarding age groups. ${ }^{13,14,16-19}$

In our study, doctors and health workers were the preferred source of medical information about vaccination. This finding is consistent with a study by Alqahtani et al, ${ }^{17,18}$ which found that $64.7 \%$ of the participants preferred doctors and health workers as a source of medical information about vaccination. In contrast to this, another study showed that only $26.7 \%$ of the participants preferred doctors and health workers while the majority preferred mass media as a source of medical information about vaccination. However, the previous 2 studies had not concentrated on a specific age group. Using health workers to provide information about vaccination increases their workload. In addition, a previous study in the Kingdom of Saudi Arabia showed that health workers had inadequate knowledge about the importance of influenza vaccine. ${ }^{15}$

Study limitations. Limited generalizability as participants were recruited from only 3 primary healthcare centers in Riyadh. A possibility of recall bias, especially in this age group is another limitation of this study. Lost or damaged paper-based questionnaire. Participants had to read the questionnaire, so illiterate individuals could not participate. These study limitations must be taken into consideration when interpreting results. A strength of the study is the high rate of participation, which enabled us to exceed the targeted sample size.

In conclusion, this study focuses on influenza vaccination in 65 years and older individuals in Saudi Arabia. The results of this study may aid in planning reforms to address gaps in healthcare. These results emphasize the need for further programs and campaigns in order to increase the level of awareness of influenza vaccination. Also, as health workers are the preferred source of information regarding influenza vaccination, health workers need to make more effort to educate patients.

Acknowledgment. We extend our sincere thanks to Amal A. Olayan and the staff at The Investigator Support Unit, Prince Naif Health Research Center, King Saud University, Riyadh, Saudi Arabia for the Editing, Proofreading Services and language review. Also, We would like to thank Editage (www. Editage.com) for English language editing.

\section{References}

1. Centres for Disease Control and Prevention. Epidemiology and prevention of vaccine-preventable disease: influenza. $13^{\text {th }}$ ed. Textbook TPBC; 2015. Available from: https://www.cdc.gov/ vaccines/pubs/pinkbook/flu.html

2. World Health Organization. Influenza (Seasonal). [Updated 2018; Accessed 2018 October 21]. Available from: http://www. who.int/mediacentre/factsheets/fs211/en/

3. World Health Organization, Weekly epidemiological record. Review of global influenza activity. [cited 2017 October]. Available from: https://apps.who.int/iris/bitstream/ handle/10665/259692/WER9250-761-779.pdf

4. Bennett JE, Dolin R, Blaser MJ. Mandell, Douglas, and Bennett's Principles and Practice of Infectious Diseases. 9th ed. Oxford (UK): Elsevier Health Sciences; 2017. p. 228.

5. Estabragh ZR, Mamas MA. The cardiovascular manifestations of influenza: a systematic review. Int J Cardiol 2013; 167: 2397-2403.

6. Joseph C, Togawa Y, Shindo N. Bacterial and viral infections associated with influenza. Influenza Other Respir Viruses 2013; 7 Suppl 2: 105-113.

7. Reed C, Chaves SS, Perez A, D'mello T, Daily Kirley P, Aragon D, et al. Complications among adults hospitalized with influenza: a comparison of seasonal influenza and the 2009 H1N1 pandemic. Clinical Infectious Diseases 2014; 59: 166-174.

8. de Lejarazu Ortiz R, Tamames S. Influenza vaccination. Effectiveness of current vaccines and future challenges. Enferm Infecc Microbiol Clin 2015; 33: 480-90.

9. Grohskopf LA, Sokolow LZ, Broder KR, Walter EB, Bresee JS, Fry AM, et al. Prevention and control of seasonal influenza with vaccines: Recommendations of the Advisory Committee on Immunization Practices - United States, 2017-18 Influenza Season. MMWR Recomm Rep 2017; 66: 1-20.

10. Peasah SK, Azziz-Baumgartner E, Breese J, Meltzer MI, Widdowson MA. Influenza cost and cost-effectiveness studies globally-a review. Vaccine 2013; 31: 5339-5348.

11. World Health Organization. Immunization coverage. [Updated 2018; Accessed 2018 October 21]. Available from: http://www. who.int/news-room/factsheets/detail/immunization-coverage

12. Nannei C, Chadwick C, Fatima H, Goldin S, Grubo M, Ganim A. Considerations for sustainable influenza vaccine production in developing countries. Vaccine 2016; 34: 5425-5429.

13. Alqahtani AS, Bondagji DM, Alshehari AA, Basyouni MH, Alhawassi TM, BinDhim NF, et al. Vaccinations against respiratory infections in Arabian Gulf countries: Barriers and motivators. World J Clin Cases 2017; 5: 212-221.

14. Assaf AM, Hammad EA, Haddadin RN. Influenza vaccination coverage rates, knowledge, attitudes, and beliefs in Jordan: A comprehensive study. Viral Immunol 2016; 29: 516-525.

15. Rehmani R, Memon JI. Knowledge, attitudes and beliefs regarding influenza vaccination among healthcare workers in a Saudi hospital. Vaccine 2010; 28: 4283-4287. 
16. Al-Khashan HI, Selim MA, Mishriky AM, Binsaeed AA. Meningitis and seasonal influenza vaccination coverage among military personnel in central Saudi Arabia. Saudi Med J 2011; 32: 159-165.

17. Alqahtani AS, Althobaity HM, Al Aboud D, Abdel-Moneim AS. Knowledge and attitudes of Saudi populations regarding seasonal influenza vaccination. J Infect Public Health 2017; 10: 897-900.

18. Sagor KH, AlAteeq MA. Beliefs, attitudes, and barriers associated with the uptake of the seasonal influenza vaccine among patients visiting primary healthcare clinics. Saudi Med J 2018; 39: 690-696.

19. Rikin S, Scott V, Shea S, LaRussa P, Stockwell MS. Influenza vaccination beliefs and practices in elderly primary care patients. J Community Health 2018; 43: 201-206.
20. Ministry of Hajj and Umrah. Services available for pilgrims in Makkah area, the holy shrines and Al-Madinah. [Updated 2018; Accessed 2018 October 21]. Available from: http://www. haj.gov.sa/en/InternalPages/Details/75

21. Ministry of Health. Seasonal Influenza Vaccination: Prevention and Vaccination. [Updated 2018; Accessed 2018 October 21]. Available from: https://www.moh.gov.sa/en/Flu/Pages/ Prevention.aspx

22. Mayet AY, Al-Shaikh GK, Al-Mandeel HM, Alsaleh NA, Hamad AF. Knowledge, attitudes, beliefs, and barriers associated with the uptake of influenza vaccine among pregnant women. Saudi Pharm J 2017; 25: 76-82.

23. General Authority for Statistics. Elderly Survey 2017. [cited 2017]. Available from: https://www.stats.gov.sa/sites/default/ files/elderly_survey_2017en.pdf

\begin{tabular}{|} 
Student Corner \\
We invite students from a variety of medical disciplines to submit original contributions based \\
on their supervised research. \\
The Student Corner of Saudi Med J aims to help students explore research opportunities \\
and network with other peers and mentors in the same field. \\
Submission Guidelines \\
Submitted Abstracts should include the following: \\
- Title should be descriptive \\
Author's names and affiliation(specify college level/year, academic degree of Senior Author) \\
Abstract must be structured and not more than 300 words \\
The following are the typical headings: \\
Objectives (background, why the study was done, specific aims) \\
Methods (setting, date of study, design, subjects, intervention and analysis) \\
Results (findings, data and statistical tests) and \\
Conclusion (general interpretation of results) \\
General Information on Abstract Submission \\
Submitted Abstracts should be co-authored by a Senior Supervisor \\
Abstracts will be reviewed by Student's Corner Section Editor \\
There is no fee to submit an Abstract \\
Ethical Approval should be provided \\
Non-indexed materials
\end{tabular}

